\title{
Spanische Kampagne in Deutschland zur Ächtung der Gewalt an Frauen
}

Spanien hat eine in Deutschland bisher unbekannte Form der Außenpolitik entwickelt. Die Abteilung für Arbeit und Migration der Spanischen Botschaft initiierte im Frühjahr 2009 eine Kampagne gegen Gewalt gegen Frauen in Deutschland mit dem Ziel, für spanische und lateinamerikanische Organisationen in Deutschland - als Multiplikatorinnen sehr pragmatische Informationen über die hiesigen Rechtsnormen und Rahmenbedingungen für Prävention und Schutz vor Gewalt für Frauen und Kinder in den Mittelpunkt zu stellen. Darüber hinaus geht es darum, die Vernetzung zwischen Regierungs- und Nichtregierungsorganisationen aus Spanien und Lateinamerika mit Sachverständigen aus Praxis und Politik in Deutschland zu fördern. Hier konnte die Botschaft auf den seit einer Dekade bestehenden engen Austausch der Kommission Gewalt gegen Frauen und Kinder des djb mit Kolleginnen der spanischen Juristinnenvereinigung Themis und anderen Akteurinnen und Akteuren in Spanien zurückgreifen.

Zum Auftakt richtete die Botschaft im März 2009 drei Informationsveranstaltungen in Frankfurt, Hannover und Berlin aus. Mitgewirkt haben - neben Expertinnen aus Bundes- und Landesministerien und vielfältigen Frauenorganisationen, die auf eine langjährig erarbeitete interkulturelle Kompetenz zurückgreifen können - aus der GewaltKommission des djb Nancy Gage-Lindner in Frankfurt und Dagmar Freudenberg in Hannover.
Beatriz Martínez Cano-Cortés, Generalsekretärin der Abteilung für Arbeit und Migration, stellte die Position Spaniens mit einer klar parteilichen Botschaft dar:

„Geschlechtsspezifische Gewalt ist keine auf die Privatsphäre beschränkte Angelegenheit. Vielmehr äußert sie sich als brutalste Form der fortbestehenden Ungleichbeit in unserer Gesellschaft. Denn es geht um Gewalt, die sich gegen Frauen richtet, und zwar aus dem einzigen Grund, weil sie Franen sind und ibre Aggressoren ibnen ein Mindestrecht auf Freiheit, Respekt und Entscheidungskompetenz absprechen. Es geht um Gewalt, die einen der schwerwiegendsten Verstöße gegen die Grundrechte wie Freiheit, Gleichheit, Leben, Sicherheit und Gleichbehandlung darstellt.

Die Spanische Regierung fühlt sich verpflichtet, zur Vorbeugung und Ausmerzung dieser Formen von Gewalt beizutragen, und siebt dringenden Handlungsbedarf. “

Die Veranstaltungen wurden rege besucht, womit ein wichtiges Ziel erreicht war: praxisorientierte Vorträge, die anschließende Diskussion und das Informationsmaterial, das jeweils mit regionalem Bezug verteilt wurde, haben Kenntnisse über die Gewalt im Geschlechterverhältnis - für viele erstmalig - vermittelt. Überwiegend noch nicht bekannt waren die Zugänge zu rechtlichen und psycho-sozialen Schutzsystemen in Deutschland - auch diese Lücke wurde erfolgreich geschlossen.
Nancy Gage-Lindner

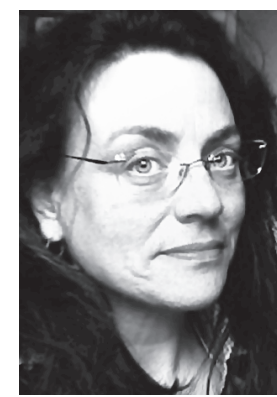

Mitglied der Kommission Gewalt gegen Frauen und Kinder des djb, Referatsleiterin im Hessischen Ministe-

rium für Arbeit, Familie und Gesundheit,

Wiesbaden

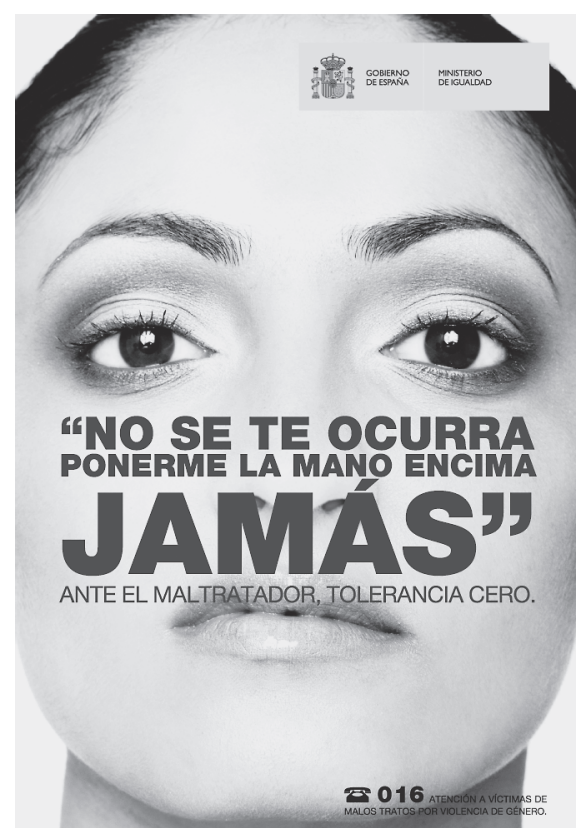

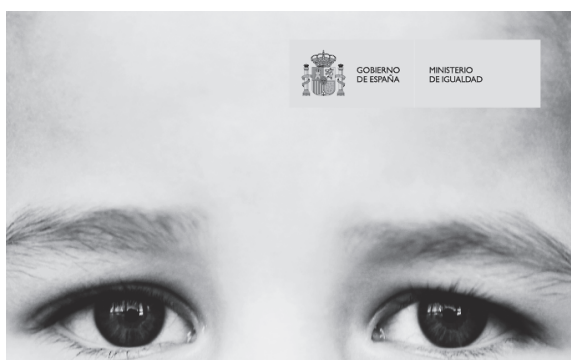
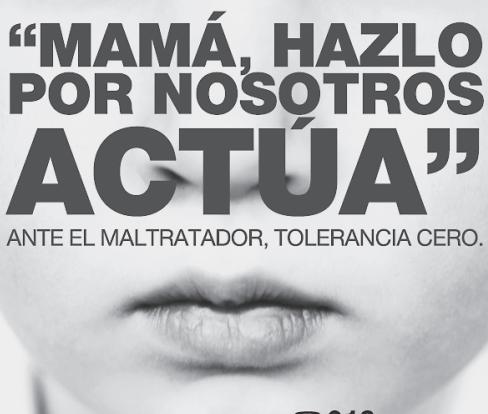

2016

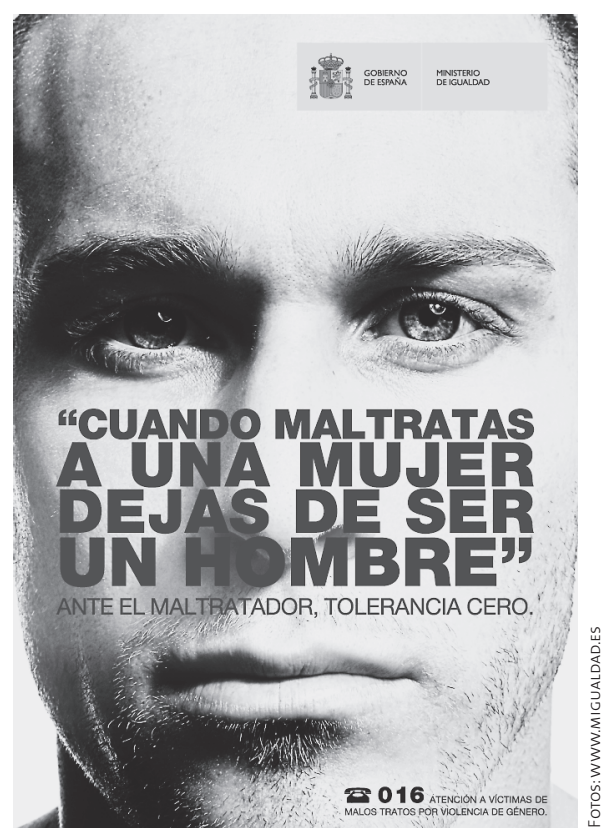

